\title{
Nanocluster evolution and mechanical properties of ion irradiated T91 ferritic- martensitic steel
}

\author{
T.P. Davis ${ }^{*}, 1$, M.A. Auger ${ }^{1,2}$, C. Hofer $^{3}$, P.A.J. Bagot ${ }^{1}$, M.P. Moody ${ }^{1}$, D.E.J. Armstrong ${ }^{1}$ \\ ${ }^{1}$ Department of Materials, University of Oxford, Parks Road, Oxford, OX1 3PH, UK \\ ${ }^{2}$ Department of Physics, Universidad Carlos III de Madrid, Leganés, Madrid, Spain \\ ${ }^{3}$ Department of Materials Science, Montanuniversität Leoben, Franz-Josef-Strasse 18, 8700 \\ Leoben, Austria
}

*Corresponding Author: thomas.davis@materials.ox.ac.uk

\begin{abstract}
Ion irradiation has been used to investigate the radiation-induced precipitation of nanoclustering and changes in mechanical properties of commercial-grade T91 ferriticmartensitic steel irradiated with $\mathrm{Fe}^{4+}$ ions up to $4.10 \mathrm{dpa}$ at $301-311{ }^{\circ} \mathrm{C}$. Atom probe tomography was used to analyse the microstructure segregation and cluster formation, while nanoindentation was used to measure the change in mechanical properties. At $0.12 \mathrm{dpa}, \mathrm{Si} / \mathrm{P}-$ rich clusters formation is observed. At $1.76 \mathrm{dpa}, \mathrm{Mn}, \mathrm{Ni}$ and $\mathrm{Si}$-rich precipitates (MNSP) are observed with a composition range that is distinctly different than the typically cited G-phase. The MNSP number density is similar to that from prior neutron irradiation studies at similar temperatures. Segregation of such species to dislocation loops and lines is also discussed. The hardness increases with dose up to 1.83 dpa before levelling off when irradiated above 1.83 dpa. Comparisons are made between the observed microstructural and mechanical property changes as a function of ion irradiated dose. The use of APT and nanoindentation, when applied in tandem, have shown to provide an insight into how radiation-induced microstructural effects can explain the observed changes in mechanical properties.
\end{abstract}

\section{INTRODUCTION}

Correct structural material selection is vital to the operation, safety and economics of any future nuclear fission or fusion reactor. The selection of any structural material relies on understanding the neutron-induced degradation during operation [1]. T91 ferritic-martensitic steel, also known as ASTM Grade 91 or Mod 9Cr-1Mo, is a candidate structural material for sodium-cooled and lead-cooled fast reactors (also known as Generation IV nuclear reactors). Microstructural and microchemical evolution is driven by neutron irradiation [2]. Characteristic microstructural features that result from neutron irradiation of T91 steel are the formation of $\mathrm{Mn}, \mathrm{Ni}$ and $\mathrm{Si}$-rich precipitates (MNSP) [3-8] (also known as G-phase $\left.\mathrm{Mn}_{6} \mathrm{Ni}_{16} \mathrm{Si}_{7}\right), \mathrm{Cr}$-rich alpha prime ( $\left.\alpha^{\prime}\right)$ formation [4,7,9-11], voids [12] and solute segregation towards dislocations [13-15]. These features are a resultant of radiation-induced precipitation and radiation-enhanced diffusion mechanism [16]. All of these features form in response to the irradiation and degrade the material properties $[17,18]$, which is clearly of concern for the safe operation of any component in-service. 
However, conducting neutron irradiation experiments is time consuming (months to years), expensive (hundreds of thousands to millions of US dollars) and produces radioactive materials. Thus, charged particle irradiation is a technique that has been developed for the simulation of neutron irradiation [19] and/or has become a surrogate for neutron irradiation [20]. Ion irradiation experiments have the added benefit that they induce little or no long-term radioactivity [21], they are low cost and generally quick (experiments can be done within a few hours). In general, it is not possible to accelerate irradiation damage to match that of neutron irradiation observed in nuclear reactors [22]; however, some researchers have introduced a "temperature shift" $[23,24]$ to compensate for the large difference between ion $\left(\sim 10^{-3}-10^{-6}\right.$ $\mathrm{dpa} / \mathrm{s})$ and neutron dose rates $\left(\sim 10^{-7}-10^{-9} \mathrm{dpa} / \mathrm{s}\right)$. Although, the effectiveness of this 'temperature shift' method to mimic neutron irradiation damage has been contested [22], it remains a topic of active investigation. Nevertheless, within this study, heavy ions will be used as it is a useful experimental tool for fine control of fundamental scientific studies on the microstructure and mechanical properties caused by ion irradiation.

It is known that $\alpha^{\prime}$ does not nucleate under self-ion irradiation of $\mathrm{Fe}-\mathrm{Cr}(9-12 \mathrm{wt} \% \mathrm{Cr})$ based alloys unless the flux is $\sim 10^{10}$ ions $/ \mathrm{cm}^{2} / \mathrm{s}$ [25]. Previous studies on heavy ion and proton irradiated T91 steels [26-28] have reported segregation of $\mathrm{Cr}$, Si and Ni to dislocations, grain boundaries and matrix interfaces. Wharry and Was [29] produced a systematic study using Scanning Transmission Electron Microscopy (STEM) and energy dispersive $\mathrm{x}$-ray spectroscopy (EDX) on the proton irradiation of T91 steel over a $300-700{ }^{\circ} \mathrm{C}$ temperature range, which revealed a peak in radiation-induced segregation (RIS) of $\mathrm{Ni}, \mathrm{Si}$ and $\mathrm{Cu}$ between $400-500{ }^{\circ} \mathrm{C}$. Mn-Ni-Si clusters have also been observed with atom probe tomography (APT) in T91 steel when subjected to proton-irradiation at 400 and $500{ }^{\circ} \mathrm{C}$ [27]. These studies reported that $\mathrm{Cr}, \mathrm{Si}, \mathrm{Ni}$ and $\mathrm{Cu}$ enrichment occurs at prior-austenite grain boundaries; however, it was not attempted to deconvolute the synergies that were at play (temperature, dose, dose-rate, ion species etc.), as it was beyond the scope of the study.

Pareige et al. [3] confirmed that $\mathrm{Cr}, \mathrm{Si}$ and $\mathrm{P}$ clusters were formed by the radiation-induced segregation (RIS) and radiation-induced precipitation mechanisms, rather than a thermodynamic mechanism. Model $\mathrm{Fe}-9 \mathrm{Cr}$ alloys were used with varying controlled impurities of $\mathrm{Si}, \mathrm{P}$ and $\mathrm{Ni}$. It was suggested that $\mathrm{P}$ played a significant role in the appearance and stabilisation of point defect clusters. It is these clusters that are thought to act as nucleation sites for Ni, Si and Cr. Gómez-Ferrer et al. [30] further investigated Mn-Ni-Si clusters in model $\mathrm{Fe}-9 \mathrm{Cr}$ alloys to determine whether they are formed by irradiation or thermodynamics. APT was used to investigate the chemical segregation of Fe-9Cr model alloys irradiated with $5 \mathrm{MeV}$ $\mathrm{Fe}^{2+}$ to 0.1 and $0.5 \mathrm{dpa}$ at $300{ }^{\circ} \mathrm{C}$. These model alloys had a controlled set of alloying additions (P, Ni and $\mathrm{Si}$ ). The authors suggested that $\mathrm{P}$ was a faster diffuser than $\mathrm{Ni}$ and $\mathrm{Si}$. It is worth noting that $\mathrm{P}$ precipitated up to $0.1 \mathrm{dpa}$ dose and sequentially saturated in number density beyond this dose. This migrating $\mathrm{P}$ can be captured by substitutional $\mathrm{P}$ within the Fe matrix, forming a stable complex [31] which can act as a nucleation point for further clustering. At an increased dose $(0.5 \mathrm{dpa}), \mathrm{P}, \mathrm{Ni}$ and $\mathrm{Si}$ were shown to preferentially cluster together. These studies used model alloys to understand the fundamental influence of P, Ni and Si to the RIS mechanisms, which could underpin the understanding of Mn-Ni-Si clusters in real-world steels. Therefore, it then naturally follows to investigate the clustering dependence on irradiation dose on such a commercially used steel. Refs $[3,30]$ did not include any Mn alloying addition and it 
is known for T91 steel that Mn clusters with Ni and Si [3-8] to form MNSPs [3-8,32,33]. In terms of specific issues in commercial $\mathrm{Fe}-\mathrm{Cr}$ systems requiring greater examination, the role of $\mathrm{Mn}, \mathrm{Ni}, \mathrm{Si}$ and $\mathrm{P}$ in T91 steel has not been studied at single specific temperature across a range of ion irradiation doses to understand the role of each solute and impurity atoms have on the evolution of the microstructure. The majority of similar investigations [3,30] have looked at model $\mathrm{Fe}-\mathrm{Cr}$ alloys to isolate each segregating element under low doses. Gómez-Ferrer et al. [30] observed Ni clustering in their APT data after heavy ion irradiation to $0.5 \mathrm{dpa}$ at 300 ${ }^{\circ} \mathrm{C}$, but did not see any clustering below this dose value. Most Fe-Cr-based commercial alloys, such as T91, have been known to form MNSP under both neutron [3,4,8,28,33-38] and proton irradiation $[3,26,27,29,39,40]$.

Furthermore, Davis et al. (2020) [33] have shown that parallels can be drawn between the understanding of precipitation in reactor pressure vessel (RPV) steels (low alloy ferriticbainitic steels [41-49]) and Fe-Cr based alloys (T91, HT9 etc) [1,2,27,50]. The major differences between RPV steels and $\mathrm{Fe}-\mathrm{Cr}$ steels are that the latter's solute contents $(\mathrm{Ni}, \mathrm{Si}$, $\mathrm{Mn}$, etc.) are typically much less and latter's neutron irradiation environmental conditions experience higher doses (>10 dpa) and temperatures $\left(300-550{ }^{\circ} \mathrm{C}\right)$. Thus, embrittlement at high doses suggests that solute segregation to and heterogeneous nucleation on dislocations could be the cause of clustering rather than solute supersaturation (since the solute contents in Fe-Cr are low) $[46,49,51-54]$.

Therefore, the objectives of this study are:

1) To use APT and nanoindentation techniques to investigate the role and segregation of $\mathrm{Mn}, \mathrm{Ni}, \mathrm{Si}$ and $\mathrm{P}$ in self-ion irradiated T91 ferritic-martensitic steel;

2) To conduct the study at a single temperature and only vary the irradiation dose;

3) To investigate any links between MNSPs and noted changes in mechanical properties.

\section{EXPERIMENTAL METHOD}

\subsection{GRADE 91 FERRITIC-MARTENSITIC STEEL}

For the material to be classified as 'Grade 91', it must meet the aforementioned international standards depending on manufacturing route taken. 80kg of ASTM F91 A182-16a (cast number 381056) was purchased from Abbey Forged Products Ltd, United Kingdom, for all material used in this study (and for future studies). ASTM A213 T91 was not chosen because the thinwalled tube geometry was impractical, thus two forged F91bars ( $\varnothing 78 \mathrm{~mm}$ by $1000 \mathrm{~mm}$ ) were delivered to the Department of Materials, University of Oxford. The steel hereon will be referred to as 'T91', as commonly stated in the extensive literature (regardless of manufacturing form) due to its primary application as tubing for fuel cladding and heat exchangers. The as-received (AR) steel was normalised at $1040{ }^{\circ} \mathrm{C}$, tempered at $730{ }^{\circ} \mathrm{C}$ and air cooled. In accordance with the British Standard EN 10204.3.1, the mechanical testing resulted in: $599 \mathrm{MPa} 0.2 \%$ proof stress, $689 \mathrm{MPa}$ tensile stress, $21 \%$ uniform elongation, and $220 \mathrm{HV}$ hardness. The manufacturer's bulk and this study's APT-measured composition are given in Table 1. The composition and mechanical testing confirmed that the steel met the ASTM A213 standard. For the ion irradiations, $\varnothing 3 \mathrm{~mm}$ by $1 \mathrm{~mm}$ discs of T91 steel samples were produced 
by electrical discharge machining and polished to a mirror finish by standard polishing techniques using silicon carbide grinding papers, diamond polish and a colloidal silica suspension. AR T91 analysed by APT had received the same thermal history aforementioned. The motivation for this was to eliminate whether Mn-Ni-Si clustering is thermally activated, rather than irradiation enhanced.

Table 1: The measured bulk composition (wt. \% and at. \%) and averaged matrix APT composition measurement and the corresponding standard deviation (at. \%) of ASTM F91 A182-16a. The APT composition and associated errors were based on the difference between multiple mass spectrum ranges.

\begin{tabular}{cccccccccc}
\hline \hline & \multicolumn{7}{c}{ T91 steel composition } \\
\hline & $\mathrm{C}$ & $\mathrm{Mn}$ & $\mathrm{P}$ & $\mathrm{S}$ & $\mathrm{Si}$ & $\mathrm{Cr}$ & $\mathrm{Mo}$ & $\mathrm{Nb}$ & $\mathrm{Cu}$ \\
\cline { 2 - 10 } Bulk (wt \%) & 0.105 & 0.420 & 0.017 & 0.020 & 0.370 & 8.620 & 0.920 & 0.070 & - \\
Bulk (at \%) & 0.483 & 0.422 & 0.030 & 0.034 & 0.727 & 9.151 & 0.529 & 0.042 & \\
APT matrix (at \%) & $0.04 \pm$ & $0.41 \pm$ & $0.07 \pm$ & - & $0.93 \pm$ & $7.98 \pm$ & $0.46 \pm$ & - & $0.02 \pm$ \\
& 0.01 & 0.01 & 0.01 & & 0.01 & 0.09 & 0.04 & & 0.01 \\
\cline { 2 - 10 } & $\mathrm{N}$ & $\mathrm{Al}$ & $\mathrm{V}$ & $\mathrm{Ti}$ & $\mathrm{Zr}$ & $\mathrm{Ni}$ & $\mathrm{Co}$ & $\mathrm{Fe}$ & \\
Bulk (wt\%) & 0.049 & 0.01 & 0.212 & 0.002 & 0.005 & 0.250 & - & $\mathrm{Bal}$. \\
Bulk (at \%) & 0.191 & 0.020 & 0.230 & 0.002 & 0.003 & 0.225 & & $\mathrm{Bal}$. \\
APT matrix (at \%) & - & $0.02 \pm$ & $0.07 \pm$ & - & - & $0.47 \pm$ & $0.01 \pm$ & $89.5 \pm$ \\
& & 0.01 & 0.01 & - & & 0.01 & 0.01 & 0.17 \\
\hline
\end{tabular}

\subsection{ION IRRADIATION}

The ion irradiation was conducted using the Dalton Accelerator for Nuclear Experiments (DAFNE) at the Dalton Cumbrian Facility, University of Manchester, United Kingdom [55]. DAFNE is a $5 \mathrm{MV}$ tandem Pelletron ion accelerator which uses a Source of Negative Ions by Caesium Sputtering (SNICS) to produce Fe ions with a 4+ charge state. The stage charge was measured by an isolated wire which was attached to the target stage. The ion flux (in ions $/ \mathrm{cm}^{2} / \mathrm{s}$ ) was calculated by the following expression:

$$
\phi=\frac{I}{\varepsilon q A}
$$

where $I$ is the current on the specimen target stage in Coulombs/s, $\varepsilon$ is the charge state, $q=$ $1.602 \times 10^{-19} \mathrm{C}$, and $A$ is the beam area.

The T91 discs prepared were subjected to two ion irradiating conditions: low and high dose. The 'low dose' experiment was irradiated with $5 \mathrm{MeV} \mathrm{Fe}^{4+}$ ions that had a $4.8 \times 10^{11} \mathrm{ions} / \mathrm{cm}^{2} / \mathrm{s}$ flux and a $3.5 \times 10^{14}$ ions $/ \mathrm{cm}^{2}$ fluence at $301.1 \pm 2.3{ }^{\circ} \mathrm{C}$ (average temperature over the experiment). This yielded an irradiation damage of $0.1 \mathrm{dpa}$ at a depth of $240 \mathrm{~nm}$ from the surface, as calculated using the Stopping and Range of Ions in Matter (SRIM) 2008 software [56]. The beam spot size was $4.7 \pm 0.5 \mathrm{~cm}^{2}$, with the beam rastered during the irradiation, with a total deposited charge on the sample of $1.097 \pm 0.010 \mathrm{mC}$. The 'high dose' experiment was irradiated with $\mathrm{Fe}^{4+}$ ions that had a $4.4 \times 10^{11}$ ions $/ \mathrm{cm}^{2} / \mathrm{s}$ flux and a $6.5 \times 10^{15}$ ions $/ \mathrm{cm}^{2}$ fluence at 
$311.9 \pm 5.2{ }^{\circ} \mathrm{C}$ (averaged over the experiment), which was $1.83 \mathrm{dpa}$ at $240 \mathrm{~nm}$ depth from the surface. The beam spot size was $6.50 \pm 0.5 \mathrm{~cm}^{2}$ and the beam was rastered during the irradiation, with a total sample charge of $27.010 \pm 0.010 \mathrm{mC}$. Best efforts were made to maintain the temperature at the target of $300{ }^{\circ} \mathrm{C}$ for both doses, and to keep a uniform ion flux. The SRIM calculation followed the recommendations provided by Stoller et al. [57]; 'Quick Kinchen-Pease calculation' was selected, displacement damage threshold values were selected from the ASTM E521 standard [58], and the lattice binding energy set to zero. The displacements-per-atom (dpa) per second per ion penetration depth (in $\mu \mathrm{m}$ ) was calculated by the following expression:

$$
\mathrm{dpa} / \mathrm{s} / \mu \mathrm{m}=\frac{v \phi}{N_{f}}
$$

where $v$ is the displacements per ion, as discussed in Ref [57], $\phi$ is the ion flux (ions $/ \mathrm{cm}^{2} / \mathrm{s}$ ) calculated by eq. 1 and $N_{f}$ is the number density as a function of penetration depth (in $\mu \mathrm{m}$ ).

\subsection{ATOM PROBE TOMOGRAPHY}

The majority of atom probe analysis was conducted with a CAMECA LEAP ${ }^{\circledR} 5000$ XR at the Department of Materials, University of Oxford, with supplementary experiments targeting grain boundaries on a CAMECA LEAP® $3000 X$ HR at the Department of Materials Science, Montanuniversität Leoben. Atom probe specimens were prepared by the lift-out technique [59] using a Zeiss NVision 40 Focused-Ion Beam (FIB) Scanning Electron Microscope (SEM). Cleaning of the specimens was performed on all samples using $2 \mathrm{kV} \mathrm{Ga}$ ions to minimise FIBinduced damage. All atom probe samples had tip diameters that were approximately between $50-100 \mathrm{~nm}$. For samples prepared in Leoben, matchsticks ( $\sim .5 \mathrm{~mm}$ diameter) of AR T91 were electropolished using $25 \%$ perchloric acid in acetic acid. Finished specimens were transferred to a ThermoFisher Versa 3D dual-beam FIB system to determine if any grain boundaries were suitably close to the tip (within 200-300 nm). Where present, Ga-ion sharpening was used to locate identified boundaries closer to the actual tip apex, and to shape the final sample. Transmission Kikuchi diffraction (TKD) scans were carried out between each milling step to determine the grain boundary misorientation angles. There was no need to change stage tilt or rotation, since suitable patterns were obtained in the same position as used for milling, ensuring fast, repeated scanning. The patterns were recorded with an EDAX Hikari XP electron backscatter diffraction (EBSD) system at an acceleration voltage of $30 \mathrm{kV}$. Data analysis was conducted using the software OIM Analysis 7 from EDAX. All suitable APT samples were analysed at a stage set-point temperature of 50-55K. A voltage pulse fraction of $20 \%$ was selected with a pulse rate of $200 \mathrm{kHz}$ and the average detection rate was set to $0.5 \%$. For specimens prepared with grain boundaries, laser pulsing was used to improve yield, running at a pulse energy of $0.6 \mathrm{~nJ}$ and a rate of $160 \mathrm{kHz}$. CAMECA IVAS ${ }^{\circledR} 3.8 .4$ was used to reconstruct all atom probe datasets used within this study. Calibration of the final reconstructed APT maps used SEM micrographs/TKD orientation maps of the final tip shape and crystallographic pole indexing.

Searching for Mn-Ni-Si clusters within APT datasets was performed by using the maximum separation method [60] and the core-link method [61] with the following parameters 
(averaged): $D_{\text {MAX }}=0.7 \mathrm{~nm}$, Order $=6, \mathrm{~N}_{\text {MIN }}=22$ and $D_{\text {erosion }}=0.35 \mathrm{~nm}$. These parameters were optimised following the method outlined in [62]. The average volume, size, number density, composition and volume fraction of clusters were calculated using the solute ions (Mn, $\mathrm{Ni}$ and $\mathrm{Si}$ ). The number density of clusters, $N_{d}$, was calculated by the following equation:

$$
N_{d}=\frac{N_{\text {ClustersDetected }-\frac{1}{2} N_{\text {EdgeClusters }}}}{V_{\text {Dataset }}}
$$

where $N_{\text {ClustersDetected }}$, is the number of clusters within the analysed reconstruction, $N_{\text {Edgeclusters }}$ is the number of clusters at the edge of the reconstruction, and $V_{\text {Dataset }}$ is the volume of the reconstruction dataset (in $\mathrm{m}^{3}$ ). Edge clusters were detected and removed using the algorithm developed by Jenkins et al. [63]. The volume of the dataset was determined by:

$V_{\text {Dataset }}=\frac{N_{\text {Ranged }} \Omega}{\eta}$

where $\Omega$ is taken as the volume of one body-centred cubic Fe atom $\left(1.178 \times 10^{-2} \mathrm{~nm}^{3}\right), N_{\text {Ranged }}$ is the number of ions ranged in a APT dataset and $\eta$ is the detection efficiency of the atom probe instrument used $\left(37 \%\right.$ and $52 \%$ for the LEAP $^{\circledR} 3000 \mathrm{X}$ HR and LEAP ${ }^{\circledR} 5000$ XR, respectively). It was assumed that the cluster number density sampled by APT analysis would have a Poisson distribution, thus the error follows $\sigma\left(N_{d}\right)=\sqrt{N_{d}}$. The volume of each cluster was assumed to be spherical and with the atomic density of bcc-Fe. The volume fraction, $f$, of the Mn-Ni-Si clusters was calculated by:

$f=\frac{N_{\text {Ranged }}^{\text {Cluster }}-N_{F e}^{\text {Ranged }}}{N_{\text {Total }}}$

where $N_{\text {Ranged }}^{\text {Cluster }}$ is the number of ranged atoms within all clusters, $N_{F e}^{\text {Ranged }}$ is the number of ranged Fe in all clusters and $N_{\text {Total }}$ is the total number of ranged atoms within the dataset.

Steels that have Ni and Si alloying additions contain mass-spectra peak overlaps on the $29 \mathrm{Da}$ peak for ${ }^{58} \mathrm{Fe}^{2+},{ }^{58} \mathrm{Ni}^{2+}$ and ${ }^{29} \mathrm{Si}^{1+}$. The APT mass-spectrum chemical identification is user defined to each peak. Thus, the overlap at 29 Da could potentially be incorporated within MNSPs. In this work, all cluster compositions include the 29 Da peak and are labelled as ${ }^{58} \mathrm{Ni}^{2+}$ (and not ${ }^{29} \mathrm{Si}^{1+}$ as the isotopic ratios for neighbouring peaks did not match natural levels), and this method has been used in previous studies $[33,64,65]$. Fe ions are also removed from all cluster calculations based on previous methods $[64,65]$.

\subsection{NANOINDENTATION}

An Agilent G200 nanoindentor was used to measure hardness by indenting a colloidal-silica polished T91 steel surface to a $2 \mu \mathrm{m}$ indentation depth at room temperature $\left(21{ }^{\circ} \mathrm{C}\right)$. A continuous stiffness measurement system with a $2 \mathrm{~nm} 39 \mathrm{~Hz}$ harmonic displacement was used to measure the modulus and hardness as a function of indentation depth. A Berkovich tip was used and the tip area coefficients were calculated from the average load-displacement data of sixteen $2 \mu \mathrm{m}$ indents into fused silica. Thus, using the known area function and contact stiffness 
as a function of tip displacement, the hardness of T91 steel was calculated as a function of tip displacement.

\section{RESULTS}

\subsection{AS-RECEIVED (AR) T91 STEEL}

The matrix volume composition reported by the atom probe reconstructions for the as-received T91 steel is found in Table 1. A typical atom probe reconstruction volume of AR T91 steel is shown in Figure 1. This ion map shows two grain boundaries decorated with $\mathrm{P}, \mathrm{Mn}, \mathrm{Si}, \mathrm{Mo}$ and $\mathrm{C}$, as expected due to the typical normalisation and tempering treatments for this type of steel. Analysis of the grain boundaries using TKD and APT is shown in Figure 2. The $38^{\circ}$ boundary was likely a prior-austenite grain boundary due to the impurity level, whereas the $50^{\circ}$ boundary was likely a martensite lath. No visual clustering of $\mathrm{Si}, \mathrm{Mn}, \mathrm{Ni}, \mathrm{Cu}, \mathrm{Cr}, \mathrm{Mo}$, or V was detected within the APT data, while prior-austenite grain boundaries were slightly enriched with $\mathrm{P}, \mathrm{Mo}, \mathrm{Ni}$ and $\mathrm{C}$, which was expected for ferritic-martensitic steels. These AR solute microstructure details provide a useful baseline for the starting microstructure before irradiation. Finally, the AR T91 steel nanoindentation hardness was found to be $4.08 \pm 0.25$ $\mathrm{GPa}$ (calculated between 230 to $250 \mathrm{~nm}$ load-displacement curve), which is shown within a later figure under the irradiation results section (see Figure 8).
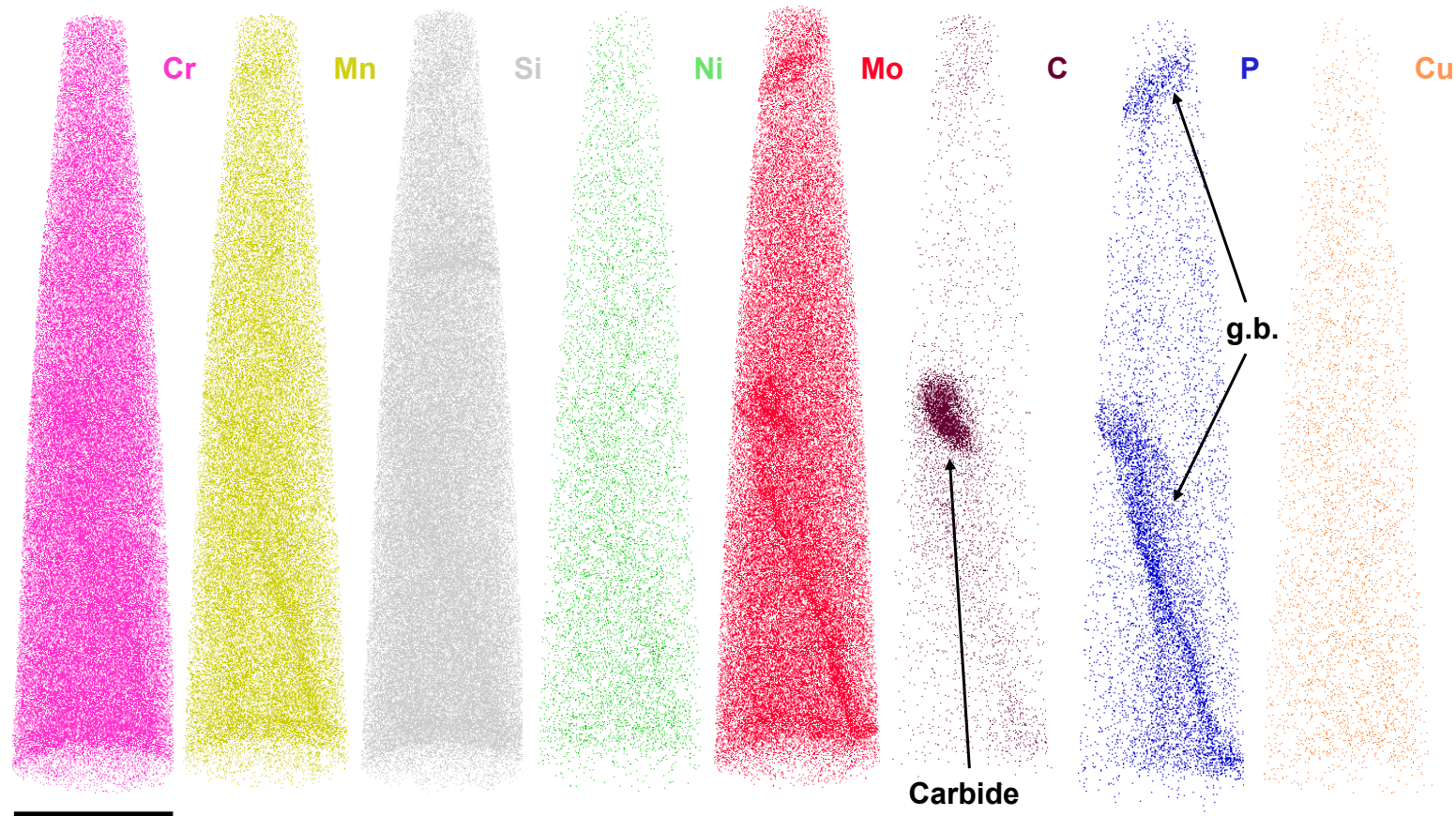

$50 \mathrm{~nm}$

Figure 1: Atom probe reconstructions of as-received T91 steel, showing segregation of Mn, Si, $N i$ and $P$ species to a grain boundary and a Mo-based carbide. 

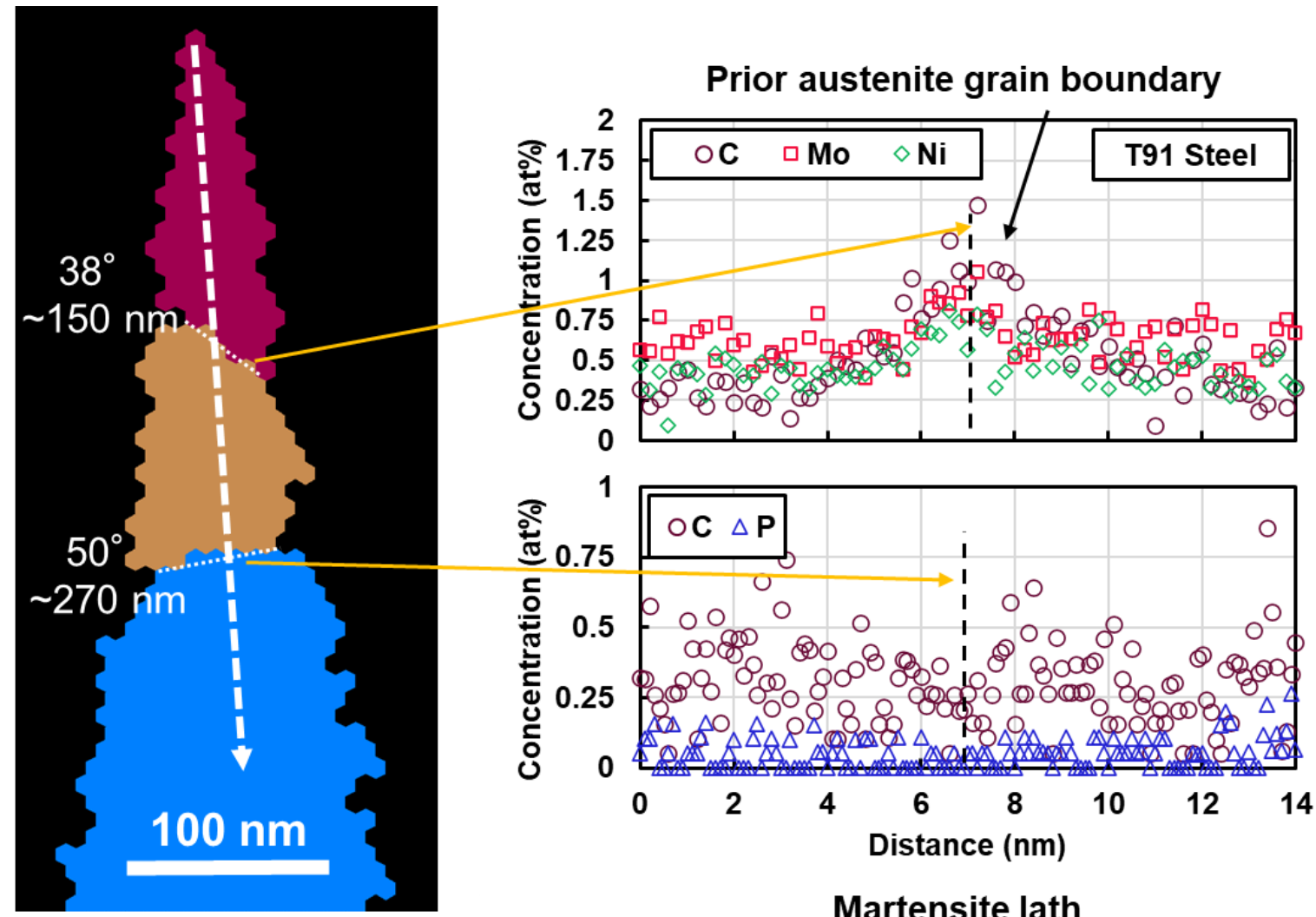

Martensite lath

Figure 2: AR T91 steel grain boundary analysis. The distances from the tip's apex is provided to give scale of the grain boundaries. The $38^{\circ}$ boundary was likely a prior-austenite grain boundary due to the increase in solute atoms ( $\mathrm{Mo}, \mathrm{C}$ and $\mathrm{Ni}$ ), whereas the $50^{\circ}$ boundary was likely a martensite lath (due to the no observed increase in $C$ and $P$ ). The dotted vertical lines on the concentration profiles represent the relevant position of the grain boundaries (white dotted lines) in the APT dataset.

\subsection{ION IRRADIATION DAMAGE PROFILES}

The ion irradiation dose (dpa) damage profiles as a function of depth from the surface were calculated by equation (1) for both 'low' and 'high' dose irradiation experiments and are shown in Figure 3. The irradiation dose (dpa) was taken as the average between $200 \mathrm{~nm}$ to $250 \mathrm{~nm}$ depth from the surface. To capture the low dose ion irradiation microstructural effects in APT, careful FIB milling was performed $100 \mathrm{~nm}$ below the irradiated surface. This region was damaged to $0.12 \mathrm{dpa}$, according to the ion damage profile in Figure 3. The motivation behind this was to determine whether Si/P plays a significant role during the initial irradiation stages during $5 \mathrm{MeV} \mathrm{Fe}^{2+}$ ion irradiation at $300{ }^{\circ} \mathrm{C}$.

APT reconstructions of the T91 steel ion irradiated to the 'low' and 'high' doses are shown in Figure 4 (a)-(c). The range of dose damages examined can be explored by selecting specific depths from the sample surface for APT analysis, as damage is strongly dependent on irradiation depth. P/Si-rich clusters can be seen after irradiation to $0.12 \mathrm{dpa}$ at $301.1 \pm 2.3{ }^{\circ} \mathrm{C}$ 
in Figure 4 (a). The formation of P/Si-rich clusters is further revealed by a $1.0 \%$ at. $\mathrm{P}$ isoconcentration surface and corresponding proxigram, as shown in Figure 5. The extent of $P$ segregation to clusters is between 3 and 4 at $\%$ at the core, which is significant considering the 0.065 at $\% \mathrm{P}$ in the bulk, as shown in Table 1.

MNSP are a defining irradiation-induced feature in ferritic-martensitic steels (such as T91 steel) and are observed in Figure 4 (b) and (c) APT reconstructions for increased irradiations of $2.62 \mathrm{dpa}$ and $4.1 \mathrm{dpa}$. By visual inspection of the reconstruction, these MNSP were enriched with $\mathrm{P}$, but no $\mathrm{Cu}$. MNSPs were not detected below a dose of $1.76 \mathrm{dpa}$, indicating there was a threshold value of dose. The average MNSP composition as a function of irradiation dose can be seen in Figure 6 on a Mn, Ni and Si ternary projection of a Fe based phase, and the composition values were calculated using the method outlined in Section 2.3. The average volume fraction, size, number density, cluster diameter and cluster composition are found in Table 2, and the methods used to calculate these values is outlined in Section 2.3.

The presence of dislocation loops was observed by $\mathrm{Si}$ decoration in the 1.0 at $\% \mathrm{Si}$ isoconcentration surface shown in Figure 7. The dislocation loops had an average diameter of $13 \mathrm{~nm} \pm 3 \mathrm{~nm}$.

The nanohardness of the T91 steel, measured as a function of irradiated dose, is shown in Figure 8. Thus, the 'low' dose nanoindentation depth value was measured at $0.10 \mathrm{dpa}$ and the 'high' dose nanoindentation depth value measured at $1.81 \mathrm{dpa}$. The nanohardness increase from AR condition to $0.10 \mathrm{dpa}$ and $1.83 \mathrm{dpa}$ was $13.1 \%$ and $21.4 \%$, respectively. The exact nanohardness values for $0 \mathrm{dpa}, 0.10 \mathrm{dpa}$ and $1.83 \mathrm{dpa}$ was $4.1 \pm 0.3 \mathrm{GPa}, 4.6 \pm 0.2 \mathrm{GPa}$, and $5.1 \pm 0.3 \mathrm{GPa}$, respectively. 

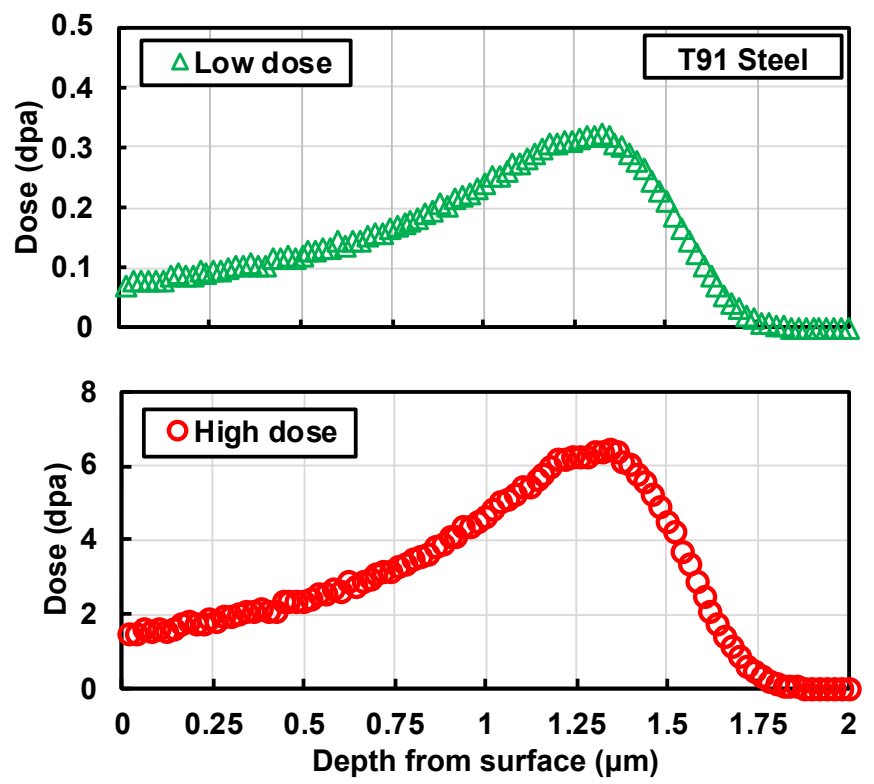

Figure 3: The $\mathrm{Fe}^{4+}$ heavy ion irradiation damage profiles of T91 steel as a function of depth at temperatures of $301.1 \pm 2.3{ }^{\circ} \mathrm{C}$ (low dose, where the dpa was $0.1 \mathrm{dpa}$ at $240 \mathrm{~nm}$ depth) and $311.9 \pm 5.2^{\circ} \mathrm{C}$ (high dose, where the dpa was 1.83 dpa at $240 \mathrm{~nm}$ depth). 
(a)

$0.12 \mathrm{dpa}$

$301.1 \pm 2.3^{\circ} \mathrm{C}$

(b)

Si decorating

dislocation

loops

$2.62 \mathrm{dpa}$

$311.9 \pm 5.2^{\circ} \mathrm{C}$

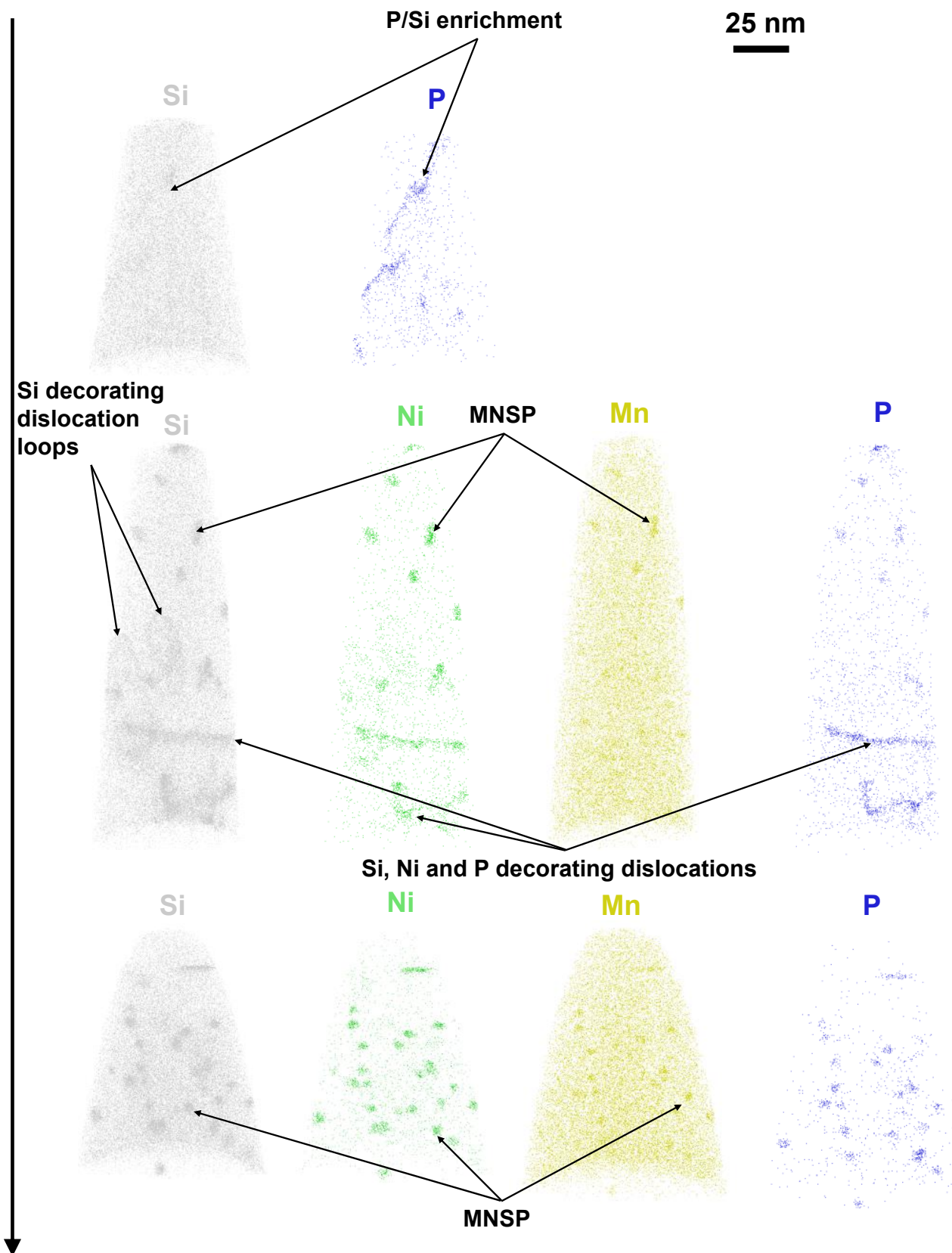

Figure 4: APT point cloud data from a dose range of T91 steel $\mathrm{Fe}^{4+}$ ion irradiated to (a) 0.12 dpa at temperatures of $301.1 \pm 2.3{ }^{\circ} \mathrm{C}$ for the 'low' dose and to (b) $2.62 \mathrm{dpa}$ and (c) $4.1 \mathrm{dpa}$ at $311.9 \pm 5.2^{\circ} \mathrm{C}$ for the 'high' dose. 


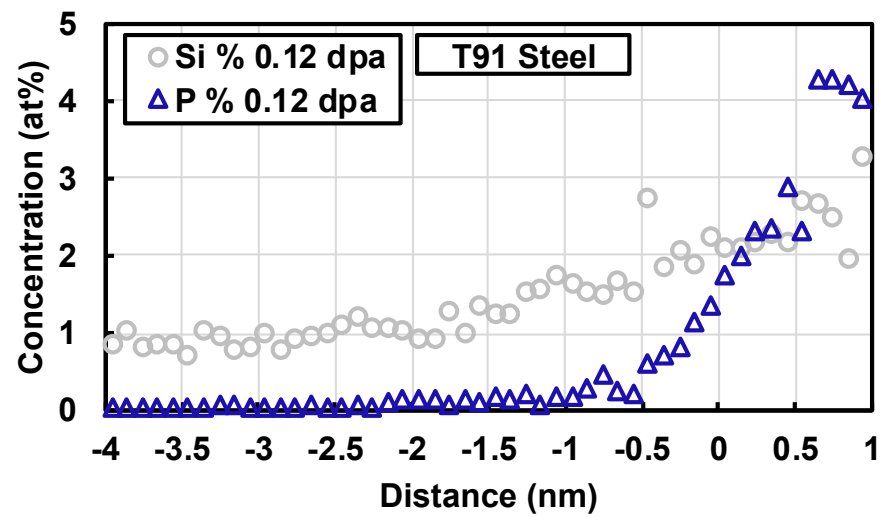

Figure 5: Proxigrams of 1.0 at.\% P isoconcentration surface from P/Si enrichment clusters, as shown in Figure 4(a) at 0.12 dpa.

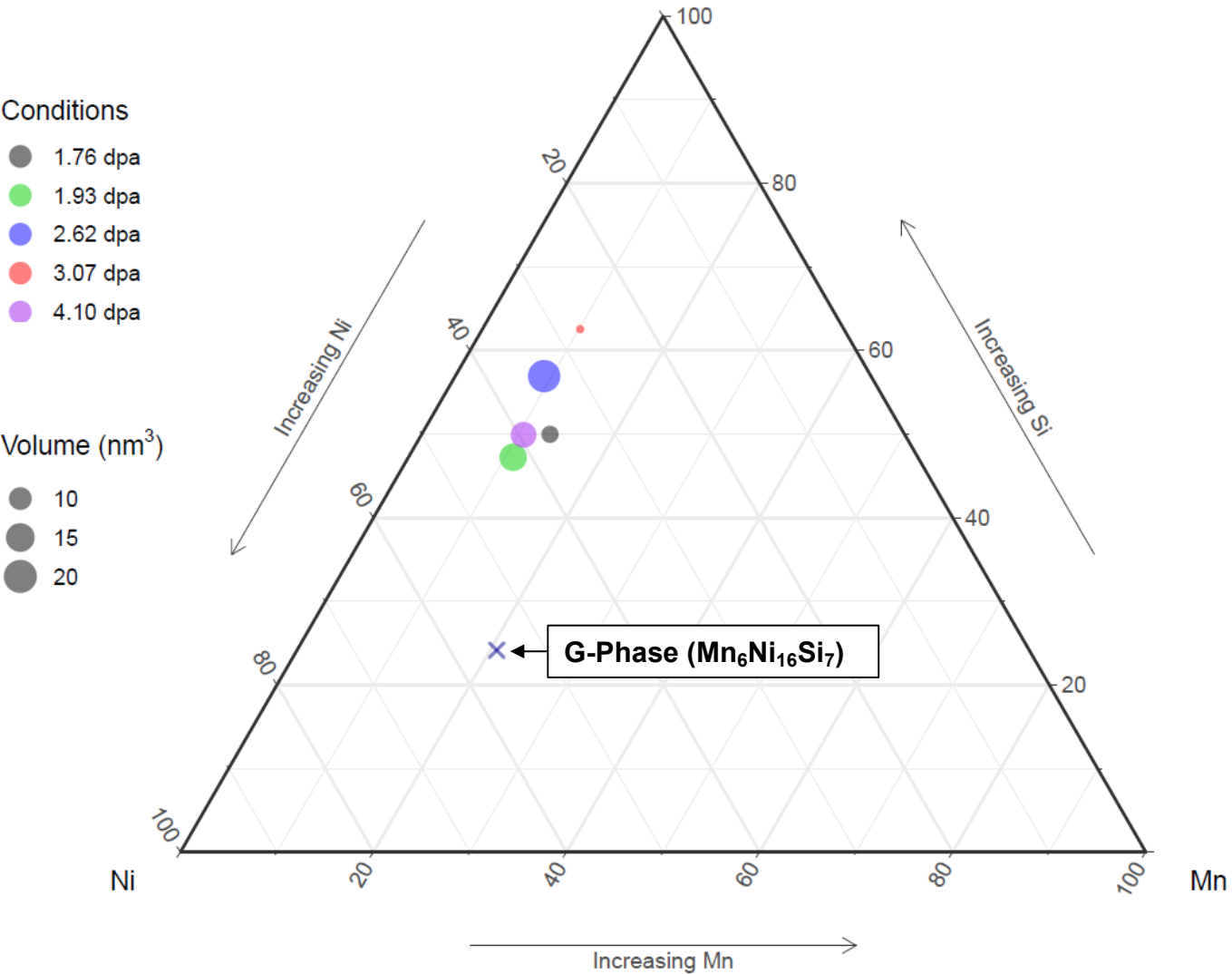

Figure 6: The Mn-Ni-Si cluster composition (in at\%) for each ion irradiation dose represented $\mathrm{Mn}, \mathrm{Ni}$, and Si ternary projection of a Fe based phase diagram. The size of the data point is scaled to the MNSP average volume $\left(\mathrm{nm}^{3}\right)$ per APT dataset and values are in Table 2 . The 'Gphase' stoichiometric phase has been provided for reference. 


\section{Fe Si}

a)

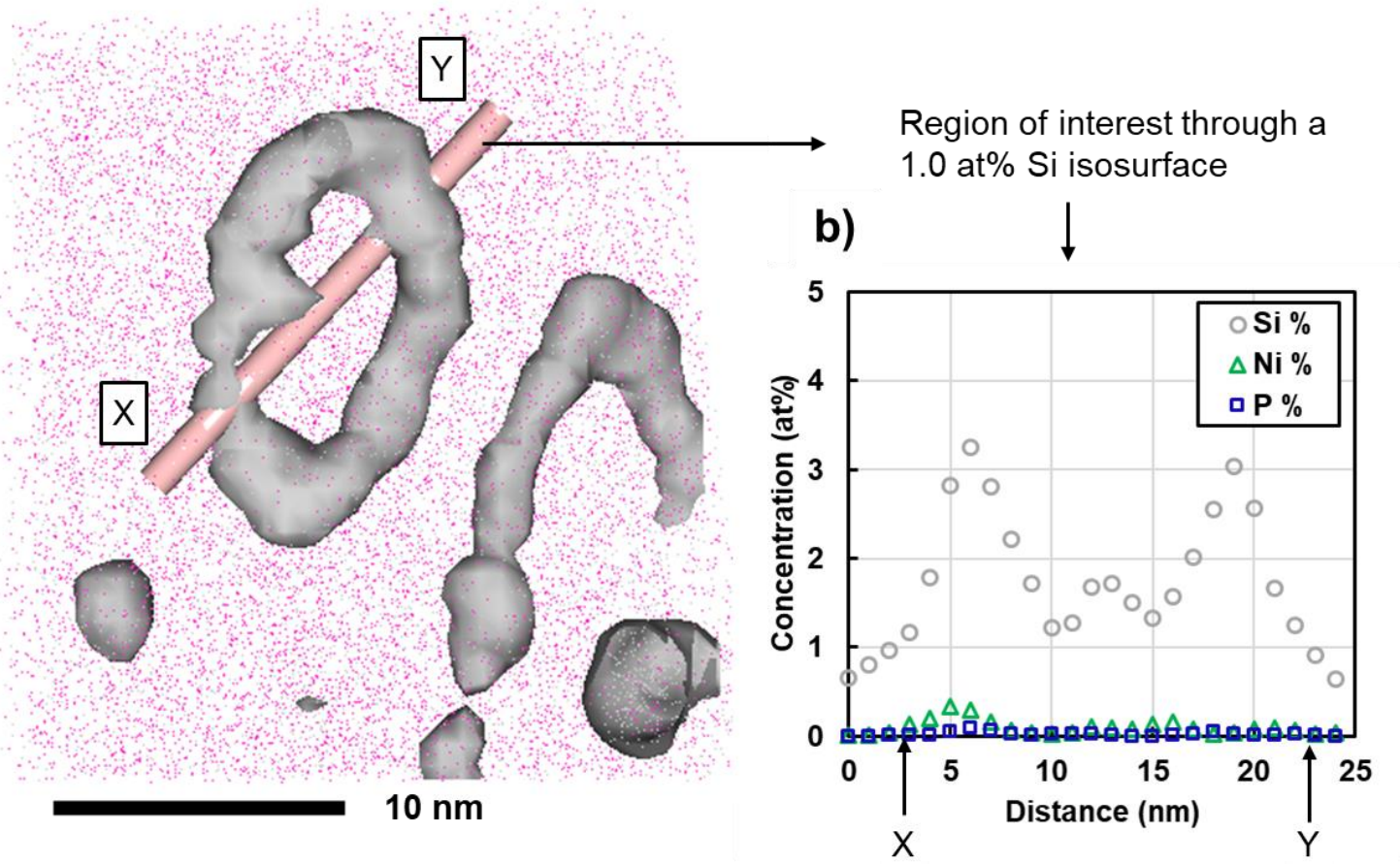

Figure 7: a) Segregation of Si to a dislocation loop in T91 steel irradiated to 2.62 dpa at 311.9 $\pm 5.2^{\circ} \mathrm{C}$. b) $1 \mathrm{D}$ line profile of the concentration (at\%) across the cylinder in a) highlighting the silicon enrichment.

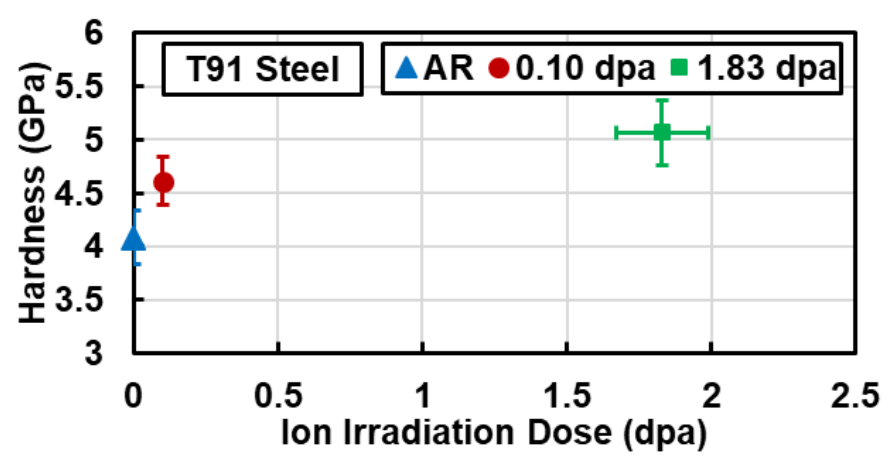

Figure 8: Nanoindentation hardness of the AR T91 steel and ion irradiated T91 steel to 0.10 and $1.83 \mathrm{dpa}$. 
Table 2: The average diameter, volume, volume fraction, and composition of MNSPs as a function of ion irradiation dose at $311.9 \pm 5.2^{\circ} \mathrm{C}$. The composition of the clusters is plotted in Figure 6.

\begin{tabular}{|l|l|l|c|c|c|c|c|}
\hline & \multicolumn{6}{|l|}{ MNSP (only solute ions, excluding Fe) } & Si $(\%)$ \\
\hline $\begin{array}{l}\text { Ion } \\
\text { dose } \\
(\mathrm{dpa})\end{array}$ & $\begin{array}{l}\text { Number } \\
\text { Density }\left(\# / \mathrm{m}^{3}\right)\end{array}$ & $\begin{array}{l}\text { Average } \\
\text { Diameter } \\
(\mathrm{nm})\end{array}$ & $\begin{array}{l}\text { Average } \\
\text { Volume } \\
\left(\mathrm{nm}^{3}\right)\end{array}$ & $\begin{array}{l}\text { Volume } \\
\text { fraction }(\%)\end{array}$ & Mn (\%) & Ni & \\
\hline 1.76 & $(2.7 \pm 0.5) 10^{23}$ & $2.4 \pm 0.2$ & $8.5 \pm 2.5$ & $0.17 \pm 0.05$ & $13.3 \pm 3.4$ & $36.7 \pm 10.6$ & $50.0 \pm 13.4$ \\
\hline 1.93 & $(2.4 \pm 0.5) 10^{23}$ & $1.3 \pm 0.4$ & $17.1 \pm 5.0$ & $0.41 \pm 0.10$ & $10.9 \pm 1.6$ & $42.0 \pm 2.3$ & $47.1 \pm 2.7$ \\
\hline 2.62 & $(1.4 \pm 0.5) 10^{23}$ & $2.4 \pm 0.4$ & $23.4 \pm 5.0$ & $1.80 \pm 0.15$ & $9.2 \pm 4.1$ & $33.9 \pm 5.7$ & $56.9 \pm 7.8$ \\
\hline 3.07 & $(1.8 \pm 0.5) 10^{23}$ & $2.0 \pm 0.4$ & $6.2 \pm 3.0$ & $0.26 \pm 0.10$ & $10.1 \pm 4.9$ & $27.3 \pm 13.1$ & $62.6 \pm 17.3$ \\
\hline 4.10 & $(1.1 \pm 0.5) 10^{23}$ & $4.0 \pm 0.4$ & $15.2 \pm 5.0$ & $0.33 \pm 0.10$ & $10.6 \pm 4.5$ & $39.5 \pm 7.7$ & $49.9 \pm 8.3$ \\
\hline
\end{tabular}

\section{DISCUSSION}

The primary aim of this study was to investigate the role that minor alloying elements and impurities have on a real-world nuclear-grade steel, such as T91 steel. Multiple AR T91 steel atom probe reconstructions were analysed, with the typical resulting microstructures shown in Figure 1 and Figure 2, which showed no visual clustering of solute elements The AR results shown in this study provide the baseline microstructure before any comparison can be made once exposed to ion irradiation. Any changes to the grain boundaries and matrix regions can thus be attributed to exposure to ion irradiation rather than thermal effects on their own.

The results shown in Figure 4(a) and Figure 5 indicate that at 0.12 dpa, Si/P segregate and form clusters, in agreement with the work of Gómez-Ferrer et al. [30]. RIS is the likely mechanism behind the segregation, as it was confirmed that no clustering of P and Si was observed in the AR T91 material undergoing the same heat treatment, as shown in Figure 1. This is also in agreement with previous studies on the role of $\mathrm{P}$ and $\mathrm{Si}$ at low heavy ion doses in steels [3]. No segregation of $\mathrm{Ni}$ was observed at these low doses, which is also in agreement with similar studies on Fe-15Cr alloys by Gómez-Ferrer et al. [30]. The findings within the study suggest that the low dose irradiation dynamics are dominated by $\mathrm{P}$ and $\mathrm{Si}$ and is independent of whether the material is a model $\mathrm{Fe}-\mathrm{Cr}$ alloy or a commercial-grade $\mathrm{Fe}-\mathrm{Cr}$ steel. This systematic study of 'low' dose ion irradiation at a single temperature has shown that both $\mathrm{P}$ and Si dominate the early stages of segregation and clustering. These clusters could provide the nucleation sites for the MNSP observed at high doses, as discussed in the next sections.

Regarding nucleation sites for MNSP, it should be noted that $\mathrm{Cu}$ impurities were detected in all APT datasets, however, no evidence of clustering was observed. The role of $\mathrm{Cu}$ clustering under neutron and ion irradiation within Fe-Cr and RPV steels has been observed and has been shown to play a significant role in the nucleation of MNSPs [33,34,42,46,66].

MNSPs were observed once the irradiation dose surpassed $1.76 \mathrm{dpa}$, with the composition (as a ratio between $\mathrm{Mn}-\mathrm{Ni}-\mathrm{Si}$ ) shown in Figure 6 and listed in Table 2. For increasing ion irradiation dose, the average diameter of MNSPs grew from $2.4 \mathrm{~nm}$ to $4.0 \mathrm{~nm}$, as shown by the 
data in Table 2. The average volume size and volume fraction appear to be uncorrelated, while the overall composition of the cluster population remains approximately constant rather than tending towards the theoretical 'G-phase' composition, and is a similar to a recent finding in neutron irradiated T91 steel [33] . The $\mathrm{MnSi}(\mathrm{Ni})$ phase field ranges from $\mathrm{Si}_{0.5} \mathrm{Mn}_{\mathrm{x}} \mathrm{Ni}_{(1-\mathrm{x})}$ where $\mathrm{x}$ varies from $\sim 0.1$ to 0.25 , as calculated by Xiong et al [47].

The Mn, Ni, Si and P solute evolution is similar to that observed in model $\mathrm{Fe}-\mathrm{Cr}$ alloys with $\mathrm{P} / \mathrm{Si} / \mathrm{Ni}$ impurities used to study their individual effects [3,30]. However, the $\mathrm{Fe}-\mathrm{Cr}$ binary alloy investigated within those studies did not contain $\mathrm{Mn}$, an alloying element that has shown clear influence on the formation of MNSP in Fe-Cr and RPV steels. Wharry et al. (2011) [27] reported that the MNSP number density was between $5-7 \times 10^{22} \mathrm{~m}^{-3}$ with a diameter of 3-5 $\mathrm{nm}$ in $2 \mathrm{MeV}$ proton irradiated T91 steel for up to $10 \mathrm{dpa}$ at $400{ }^{\circ} \mathrm{C}$. The number density reported within this study is $1.1-2.7 \times 10^{23} \mathrm{~m}^{-3}$ with an average diameter $1.3-4.0 \mathrm{~nm}$ (Table 2 ). The major difference between these two studies is Wharry et al. conducting the experiment at $400{ }^{\circ} \mathrm{C}$ whereas this study was conducted at $311.9 \pm 5.2{ }^{\circ} \mathrm{C}$; as expected with an increase in temperature, the number density of the MNSP would decrease due to the increase in the rate of solute diffusion. Furthermore, the MNSP number density $\left(1.1-2.7 \times 10^{23} \mathrm{~m}^{-3}\right)$, average radii $(0.65-2 \mathrm{~nm})$, and volume fraction $(0.17-0.41 \%)$, if the value at $2.62 \mathrm{dpa}$ is removed due to the small APT dataset) are in good agreement with 2.14 dpa neutron irradiated T91 $327^{\circ} \mathrm{C}$ [33] MNSP number density $\left(3.1 \pm 0.7 \times 10^{23} \mathrm{~m}^{-3}\right)$, average radii $(1.1 \mathrm{~nm})$, and volume fraction $(0.26$ $\%)$. The agreement indicates that the methods used in both studies have provided further confidence in ion irradiation as a potential tool to predict radiation-induced effects in reactor component materials without conducting neutron experiments.

Ion damage cascades form dislocation loops [14] at $300^{\circ} \mathrm{C}$. At the 'high' dose, Si segregated to the periphery of dislocations as shown in Figure 7(a). These Si-decorated dislocations have either a line or loop formation, and these loops have an average diameter of $13 \mathrm{~nm} \pm 3 \mathrm{~nm}$. Si has been observed to segregate, along with $\mathrm{Ni}$, to dislocations in ferritic-martensitic steels [67]. Conversely, $\mathrm{Cr}$ has been modelled to decorate loops in irradiated $\mathrm{Fe}-\mathrm{Cr}$ alloys [68] but this has not been observed in the current work. Additionally, not all of the dislocations (loop and line type) observed in the APT datasets had P-enriched peripheries; line dislocations were decorated with $\mathrm{P}$ and $\mathrm{Ni}$, as shown in Figure 4(c) following 2.62 dpa irradiation, but loop dislocations were observed to be decorated only with $\mathrm{Si}$ (shown in the same figure for $2.62 \mathrm{dpa}$ ). A suggestion to explain this result is that these $\mathrm{Si}$-enriched loop dislocations were introduced by irradiation displacement damage rather than by the manufacturing process.

T91 steel has a ferritic-martensitic microstructure with a high dislocation density that was formed during the tempering stage. Prior to irradiation, these pre-existing dislocations would be the first to be decorated with $\mathrm{P}$ due to the large diffusion affinity to form stable complexes [31]. From the low dose irradiation at $0.12 \mathrm{dpa}, \mathrm{P}$ has already clustered and, thus, becomes depleted within the matrix. The formation of loop dislocations by displacement damage would form within this now P-depleted matrix. It is therefore not possible for P to decorate the newly formed dislocation loop. This provides a feasible explanation for the observation of no $\mathrm{P}$ decorated dislocation loops following irradiation at $300{ }^{\circ} \mathrm{C}$. 
The nanohardness increase from AR condition to $0.10 \mathrm{dpa}$ and $1.83 \mathrm{dpa}$ was $13.1 \%$ and 21.4 $\%$, respectively, as shown in Figure 8 and section 3.2. It is well known that irradiation damage produces dislocation loops, increasing the dislocation density. In addition to the dislocation density, the APT results show, even at low doses, that the formation of P and Si clusters likely contribute to the hardening of the steel. These clusters act as dislocation motion barriers; however, direct observation of this pinning would involve utilising transmission electron microscopy (TEM) to image the plastic zone beneath the nanoindent. This is beyond the scope of this study, however, Davis et al. [69] performed a similar study in an oxide dispersion strengthened steel, imaging the dislocations becoming pinned by nanoparticles beneath nanoindents. The size of the nanoparticles was $2-5 \mathrm{~nm}$, which is comparable to the size of the MNSP observed within this study.

The hardness response as a function of irradiation dose was not linear, as shown in Figure 8. The number density of MNSP remained within the same order of magnitude and did not increase with dose. The increase in hardness can be attributed to dislocation pinning on these MNSP and dislocation loops becoming entangled during deformation. The density of these clusters should not be expected to increase after further irradiation as the matrix has been depleted of Mn, Ni and Si to form new clusters. This would lead to the observed tail-off in hardening from 0.1 dpa to $1.83 \mathrm{dpa}$ as shown in Figure 8. Any further increase in hardness with irradiation dose would be a resultant of solute segregation towards dislocations rather than the nucleation of more MNSPs within the matrix. This study highlights that solute segregation to and on dislocations in T91 steel occurs under heavy ion irradiation at $311.9 \pm 5.2^{\circ} \mathrm{C}$ and could contribute significantly to the embrittlement of this steel.

It should be noted that there was no observation of $\alpha^{\prime}$ precipitation in any of the APT datasets. This was as-expected because the kinetics do not enable the formation due to the high dose rate used [25].

\section{CONCLUSION}

Overall, this ion irradiation study has provided an insight into how minor alloying elements and impurities evolve as a function of irradiation dose whilst keeping the temperature and irradiation dose rate as fixed parameters by using APT and nanoindentation. The key findings from this were:

- Prior to irradiation, the AR T91 steel state showed no clustering of Mn, Ni, Si and P, with minor enrichment of impurities and alloying elements at the prior-austenite gain boundaries.

- MNSPs were observed once the ion dose exceeded $1.76 \mathrm{dpa}$ at $311.9 \pm 5.2^{\circ} \mathrm{C}$.

- The MNSP had a distantly different composition to the typical cited 'G-Phase', which falls near the $\mathrm{MnSi}(\mathrm{Ni})$ phase field (which is ranged from $\mathrm{Si}_{0.5} \mathrm{Mn}_{\mathrm{x}} \mathrm{Ni}_{(1-\mathrm{x})}$ where $\mathrm{x}$ varies from $\sim 0.1$ to 0.25 [47])

- The average diameter of MNSPs grew with dose, while the average size and volume fraction appeared uncorrelated with irradiation dose. The number density, radii, and volume fractions agreed well with previous neutron irradiation T91 data. 
- Dislocations loops were decorated with Si when irradiated to 2.62 dpa at $311.9 \pm 5.2$ ${ }^{\circ} \mathrm{C}$.

- At $0.12 \mathrm{dpa}$, formation of $\mathrm{Si} / \mathrm{P}$-rich clusters were observed and increased the nanohardness by $13.1 \%$ from the AR condition. The hardness did not increase linearly as a function of dose but rather tailed off between 0.1 to $1.83 \mathrm{dpa}$.

Overall, this study has demonstrated the usefulness of ion irradiation to observe and understand the role of solute ions and impurities in commercial grade ferritic-martensitic steels, particularly when part of a controlled study varying irradiation over a number of dose conditions. The APT and nanoindentation techniques have shown that, when applied in tandem, they can provide an insight into how microstructural changes under irradiation can explain observed changes in mechanical properties.

\section{ACKNOWLEDGEMENTS}

T. P. Davis is funded by the Clarendon Scholarship from the University of Oxford and Engineering and Physical Sciences Research Council Fusion Centre for Doctorial Training [EP/L01663X/1]. APT was supported by EPSRC grant EP/M022803/1 "A LEAP 5000XR for the UK National Atom Probe Facility." The authors acknowledge use of characterisation facilities within the David Cockayne Centre for Electron Microscopy, Department of Materials, University of Oxford, alongside financial support provided by the Henry Royce Institute (Grant ref EP/R010145/1). Funding of the Austrian BMK in the framework of the program "Production of the future" and the "BMK Professorship for Industry" are gratefully acknowledged. P.A.J. Bagot gratefully acknowledges support from the EU's Erasmus+ Programme to carry out TKD experiments with C. Hofer at Montanuniversität Leoben.

\section{REFERENCES}

[1] T.P. Davis, Review of the iron-based materials applicable for the fuel and core of future Sodium Fast Reactors (SFR), Off. Nucl. Regul. ONR-RRR-088 (2018) 1-52. http://www.onr.org.uk/documents/2018/onr-rrr-088.pdf.

[2] R.L. Klueh, D.R. Harries, High-Chromium Ferritic and Martensitic Steels for Nuclear Applications, 2001. https://doi.org/10.1520/mono3-eb.

[3] C. Pareige, V. Kuksenko, P. Pareige, Behaviour of P, Si, Ni impurities and Cr in self ion irradiated Fe-Cr alloys - Comparison to neutron irradiation, J. Nucl. Mater. 456 (2015) 471-476. https://doi.org/10.1016/j.jnucmat.2014.10.024.

[4] J. Van Den Bosch, O. Anderoglu, R. Dickerson, M. Hartl, P. Dickerson, J.A. Aguiar, P. Hosemann, M.B. Toloczko, S.A. Maloy, SANS and TEM of ferritic-martensitic steel T91 irradiated in FFTF up to 184 dpa at $413{ }^{\circ} \mathrm{c}$, J. Nucl. Mater. 440 (2013) 9197. https://doi.org/10.1016/j.jnucmat.2013.04.025.

[5] O. Anderoglu, J. Van Den Bosch, P. Hosemann, E. Stergar, B.H. Sencer, D.

Bhattacharyya, R. Dickerson, P. Dickerson, M. Hartl, S.A. Maloy, Phase stability of an HT-9 duct irradiated in FFTF, J. Nucl. Mater. 430 (2012) 194-204. https://doi.org/10.1016/j.jnucmat.2012.06.038.

[6] S. Rogozhkin, A. Nikitin, N. Orlov, A. Bogachev, O. Korchuganova, A. Aleev, A. 
Zaluzhnyi, T. Kulevoy, R. Lindau, A. Moslang, P. Vladimirov, Evolution of microstructure in advanced ferritic-martensitic steels under irradiation: the origin of low temperature radiation embrittlement S., MRS Adv. 2 (2017) 1143-1155. https://doi.org/10.1017/CBO9781107415324.004.

[7] M.J. Swenson, J.P. Wharry, Nanocluster irradiation evolution in Fe-9\%Cr ODS and ferritic-martensitic alloys, J. Nucl. Mater. 496 (2017) 24-40. https://doi.org/10.1016/j.jnucmat.2017.08.045.

[8] L. Tan, B.K. Kim, Y. Yang, K.G. Field, S. Gray, M. Li, Microstructural evolution of neutron-irradiated T91 and NF616 to $\sim 4.3$ dpa at $469{ }^{\circ} \mathrm{C}$, J. Nucl. Mater. 493 (2017) 12-20. https://doi.org/10.1016/j.jnucmat.2017.05.041.

[9] M. Bachhav, G. Robert Odette, E.A. Marquis, $\alpha^{\prime}$ precipitation in neutron-irradiated FeCr alloys, Scr. Mater. 74 (2014) 48-51. https://doi.org/10.1016/j.scriptamat.2013.10.001.

[10] E.R. Reese, M. Bachhav, P. Wells, T. Yamamoto, G. Robert Odette, E.A. Marquis, On $\alpha^{\prime}$ precipitate composition in thermally annealed and neutron-irradiated $\mathrm{Fe}-9-18 \mathrm{Cr}$ alloys, J. Nucl. Mater. 500 (2018) 192-198. https://doi.org/10.1016/j.jnucmat.2017.12.036.

[11] D. Bhattacharyya, T. Yamamoto, P. Wells, E. Marquis, M. Bachhav, Y. Wu, J. Davis, A. Xu, G.R. Odette, Microstructural changes and their effect on hardening in neutron irradiated Fe-Cr alloys, J. Nucl. Mater. 519 (2019) 274-286. https://doi.org/10.1016/j.jnucmat.2019.03.022.

[12] M.B. Toloczko, F.A. Garner, C.R. Eiholzer, Irradiation creep and swelling of the US fusion heats of HT9 and $9 \mathrm{Cr}-1 \mathrm{Mo}$ to $208 \mathrm{dpa}$ at $\sim 400^{\circ} \mathrm{C}$, J. Nucl. Mater. 212-215 (1994) 604-607. https://doi.org/10.1016/0022-3115(94)90131-7.

[13] V. Kuksenko, C. Pareige, C. Genevois, P. Pareige, Characterisation of Cr, Si and P distribution at dislocations and grain-boundaries in neutron irradiated $\mathrm{Fe}-\mathrm{Cr}$ model alloys of low purity, J. Nucl. Mater. 434 (2013) 49-55. https://doi.org/10.1016/j.jnucmat.2012.11.027.

[14] J.C. Haley, S. de Moraes Shubeita, P. Wady, A.J. London, G.R. Odette, S. LozanoPerez, S.G. Roberts, Microstructural examination of neutron, proton and self-ion irradiation damage in a model Fe9Cr alloy, J. Nucl. Mater. (2020) 152130. https://doi.org/10.1016/j.jnucmat.2020.152130.

[15] J.C. Haley, F. Liu, E. Tarleton, A.C.F. Cocks, G.R. Odette, S. Lozano-Perez, S.G. Roberts, Helical dislocations: Observation of vacancy defect bias of screw dislocations in neutron irradiated Fe-9Cr, Acta Mater. 181 (2019) 173-184. https://doi.org/10.1016/j.actamat.2019.09.031.

[16] S.J. Zinkle, G.S. Was, Materials challenges in nuclear energy, Acta Mater. 61 (2013) 735-758. https://doi.org/10.1016/J.ACTAMAT.2012.11.004.

[17] R.L. Klueh, J.M. Vitek, Elevated-Temperature tensile properties of irradaited 9Cr1 MoVNb Steel, J. Nucl. Mater. 132 (1985) 27-31.

[18] J.J. Kai, R.L. Klueh, Microstructural analysis of neutron-irradiated martensitic steels, J. Nucl. Mater. 230 (1996) 116-123. https://doi.org/10.1016/0022-3115(96)00165-1.

[19] J. Gan, G.S. Was, Microstructure evolution in austenitic Fe-Cr-Ni alloys irradiated with rotons: Comparison with neutron-irradiated microstructures, J. Nucl. Mater. 297 (2001) 161-175. https://doi.org/10.1016/S0022-3115(01)00615-8.

[20] P. Hosemann, D. Frazer, M. Fratoni, A. Bolind, M.F. Ashby, Materials selection for 
nuclear applications: Challenges and opportunities, Scr. Mater. 143 (2018) 181-187. https://doi.org/10.1016/j.scriptamat.2017.04.027.

[21] G.S. Was, Challenges to the use of ion irradiation for emulating reactor irradiation, J. Mater. Res. 30 (2015) 1158-1182. https://doi.org/10.1557/jmr.2015.73.

[22] S.J. Zinkle, L.L. Snead, Opportunities and limitations for ion beams in radiation effects studies: Bridging critical gaps between charged particle and neutron irradiations, Scr. Mater. 143 (2018) 154-160. https://doi.org/10.1016/j.scriptamat.2017.06.041.

[23] L.K. Mansur, Correlation of neutron and heavy-ion damage. II. The predicted temperature shift if swelling with changes in radiation dose rate, J. Nucl. Mater. 78 (1978) 156-160. https://doi.org/10.1016/0022-3115(78)90514-7.

[24] G.S. Was, Z. Jiao, E. Getto, K. Sun, A.M. Monterrosa, S.A. Maloy, O. Anderoglu, B.H. Sencer, M. Hackett, Emulation of reactor irradiation damage using ion beams, Scr. Mater. 88 (2014) 33-36. https://doi.org/10.1016/j.scriptamat.2014.06.003.

[25] O. Tissot, C. Pareige, E. Meslin, B. Décamps, J. Henry, Influence of injected interstitials on $\alpha^{\prime}$ precipitation in Fe-Cr alloys under self-ion irradiation, Mater. Res. Lett. 5 (2017) 117-123. https://doi.org/10.1080/21663831.2016.1230896.

[26] Z. Jiao, V. Shankar, G.S. Was, Phase stability in proton and heavy ion irradiated ferritic-martensitic alloys, J. Nucl. Mater. 419 (2011) 52-62. https://doi.org/10.1016/j.jnucmat.2011.08.020.

[27] J.P. Wharry, Z. Jiao, V. Shankar, J.T. Busby, G.S. Was, Radiation-induced segregation and phase stability in ferritic-martensitic alloy T 91, J. Nucl. Mater. 417 (2011) 140144. https://doi.org/10.1016/j.jnucmat.2010.12.052.

[28] S.B. Adisa, R. Blair, M.J. Swenson, Comparison of microstructure evolution in Fe2+ or neutron-irradiated T91 at $500^{\circ} \mathrm{C}$, Materialia. 12 (2020) 100770. https://doi.org/10.1016/j.mtla.2020.100770.

[29] J.P. Wharry, G.S. Was, A systematic study of radiation-induced segregation in ferriticmartensitic alloys, J. Nucl. Mater. 442 (2013) 7-16. https://doi.org/10.1016/j.jnucmat.2013.07.071.

[30] B. Gómez-Ferrer, C. Heintze, C. Pareige, On the role of Ni, Si and P on the nanostructural evolution of FeCr alloys under irradiation, J. Nucl. Mater. 517 (2019) 35-44. https://doi.org/10.1016/j.jnucmat.2019.01.040.

[31] C. Domain, C.S. Becquart, Diffusion of phosphorus in $\alpha-\mathrm{Fe}$ : An ab initio study, Phys. Rev. B - Condens. Matter Mater. Phys. 71 (2005) 1-13. https://doi.org/10.1103/PhysRevB.71.214109.

[32] Z. Jiao, S. Taller, K. Field, G. Yeli, M.P. Moody, G.S. Was, Microstructure evolution of T91 irradiated in the BOR60 fast reactor, J. Nucl. Mater. 504 (2018) 122-134. https://doi.org/10.1016/j.jnucmat.2018.03.024.

[33] T.P. Davis, M.A. Auger, N. Almirall, P. Hosemann, G.R. Odette, M.P. Moody, P.A.J. Bagot, D.E.J. Armstrong, Atom probe characterisation of segregation driven $\mathrm{Cu}$ and Mn-Ni-Si co-precipitation in neutron irradiated T91 tempered-martensitic steel, ArXiv. 2007.10710 (2020). https://arxiv.org/abs/2007.10710.

[34] G.S. Was, J.P. Wharry, B. Frisbie, B.D. Wirth, D. Morgan, J.D. Tucker, T.R. Allen, Assessment of radiation-induced segregation mechanisms in austenitic and ferriticmartensitic alloys, J. Nucl. Mater. 411 (2011) 41-50. https://doi.org/10.1016/j.jnucmat.2011.01.031.

[35] J.H. Ke, H. Ke, G.R. Odette, D. Morgan, Cluster dynamics modeling of Mn-Ni-Si 
precipitates in ferritic-martensitic steel under irradiation, J. Nucl. Mater. 498 (2018) 83-88. https://doi.org/10.1016/j.jnucmat.2017.10.008.

[36] E. Getto, Z. Jiao, A.M. Monterrosa, K. Sun, G.S. Was, Effect of irradiation mode on the microstructure of self-ion irradiated ferritic-martensitic alloys, J. Nucl. Mater. 465 (2015) 116-126. https://doi.org/10.1016/j.jnucmat.2015.05.016.

[37] C. Zheng, E.R. Reese, K.G. Field, E. Marquis, S.A. Maloy, D. Kaoumi, Microstructure response of ferritic/martensitic steel HT9 after neutron irradiation: effect of dose, J. Nucl. Mater. 523 (2019) 421-433. https://doi.org/10.1016/j.jnucmat.2019.06.019.

[38] C. Zheng, E.R. Reese, K.G. Field, T. Liu, E.A. Marquis, S.A. Maloy, D. Kaoumi, Microstructure response of ferritic/martensitic steel HT9 after neutron irradiation: Effect of temperature, J. Nucl. Mater. 528 (2020) 151845. https://doi.org/10.1016/j.jnucmat.2019.151845.

[39] G. Gupta, Z. Jiao, A.N. Ham, J.T. Busby, G.S. Was, Microstructural evolution of proton irradiated T91, J. Nucl. Mater. 351 (2006) 162-173. https://doi.org/10.1016/j.jnucmat.2006.02.028.

[40] Z. Jiao, G.S. Was, Segregation behavior in proton- and heavy-ion-irradiated ferriticmartensitic alloys, Acta Mater. 59 (2011) 4467-4481. https://doi.org/10.1016/j.actamat.2011.03.070.

[41] G.R. Odette, Radiation induced microstructural evolution in reactor pressure vessel steels, Mater. Res. Soc. Symp. - Proc. 373 (1995) 137-148. https://doi.org/10.1557/proc-373-137.

[42] G.R. Odette, T. Yamamoto, T.J. Williams, R.K. Nanstad, C.A. English, On the history and status of reactor pressure vessel steel ductile to brittle transition temperature shift prediction models, J. Nucl. Mater. 526 (2019) 151863. https://doi.org/10.1016/j.jnucmat.2019.151863.

[43] G.R. Odette, On the dominant mechanism of irradiation embrittlement of reactor pressure vessel steels, Scr. Metall. (1983).

[44] G.R. Odette, B.D. Wirth, A computational microscopy study of nanostructural evolution in irradiated pressure vessel steels, J. Nucl. Mater. (1997). https://doi.org/10.1016/S0022-3115(97)00267-5.

[45] S. Shu, P.B. Wells, N. Almirall, G.R. Odette, D.D. Morgan, Thermodynamics and kinetics of core-shell versus appendage co-precipitation morphologies: An example in the Fe-Cu-Mn-Ni-Si system, Acta Mater. 157 (2018) 298-306. https://doi.org/10.1016/j.actamat.2018.07.037.

[46] M.K. Miller, K.F. Russell, M.A. Sokolov, R.K. Nanstad, APT characterization of irradiated high nickel RPV steels, J. Nucl. Mater. 361 (2007) 248-261. https://doi.org/10.1016/j.jnucmat.2006.12.015.

[47] W. Xiong, H. Ke, R. Krishnamurthy, P. Wells, L. Barnard, G.R. Odette, D. Morgan, Thermodynamic models of low-temperature $\mathrm{Mn}-\mathrm{Ni}-\mathrm{Si}$ precipitation in reactor pressure vessel steels, MRS Commun. 4 (2014) 101-105. https://doi.org/10.1557/mrc.2014.21.

[48] K. Lindgren, M. Boåsen, K. Stiller, P. Efsing, M. Thuvander, Evolution of precipitation in reactor pressure vessel steel welds under neutron irradiation, J. Nucl. Mater. 488 (2017) 222-230. https://doi.org/10.1016/j.jnucmat.2017.03.019.

[49] N. Almirall, P.B. Wells, S. Pal, P.D. Edmondson, T. Yamamoto, K. Murakami, G.R. Odette, The mechanistic implications of the high temperature, long time thermal 
stability of nanoscale Mn-Ni-Si precipitates in irradiated reactor pressure vessel steels, Scr. Mater. 181 (2020) 134-139. https://doi.org/10.1016/j.scriptamat.2020.02.027.

[50] R.L. Klueh, A.T. Nelson, Ferritic/martensitic steels for next-generation reactors, J. Nucl. Mater. 371 (2007) 37-52. https://doi.org/10.1016/j.jnucmat.2007.05.005.

[51] E. Meslin, A. Barbu, L. Boulanger, B. Radiguet, P. Pareige, K. Arakawa, C.C. Fu, Cluster-dynamics modelling of defects in $\alpha$-iron under cascade damage conditions, J. Nucl. Mater. 382 (2008) 190-196. https://doi.org/10.1016/J.JNUCMAT.2008.08.010.

[52] G. Bonny, D. Terentyev, E.E. Zhurkin, L. Malerba, Monte Carlo study of decorated dislocation loops in FeNiMnCu model alloys, J. Nucl. Mater. 452 (2014) 486-492. https://doi.org/10.1016/J.JNUCMAT.2014.05.051.

[53] N. Almirall, P.B. Wells, T. Yamamoto, K. Wilford, T. Williams, N. Riddle, G.R. Odette, Precipitation and hardening in irradiated low alloy steels with a wide range of Ni and Mn compositions, Acta Mater. 179 (2019) 119-128. https://doi.org/10.1016/j.actamat.2019.08.027.

[54] P.B. Wells, T. Yamamoto, B. Miller, T. Milot, J. Cole, Y. Wu, G.R. Odette, Evolution of manganese-nickel-silicon-dominated phases in highly irradiated reactor pressure vessel steels, Acta Mater. 80 (2014) 205-219. https://doi.org/10.1016/j.actamat.2014.07.040.

[55] P.T. Wady, A. Draude, S.M. Shubeita, A.D. Smith, N. Mason, S.M. Pimblott, E. Jimenez-Melero, Accelerated radiation damage test facility using a $5 \mathrm{MV}$ tandem ion accelerator, Nucl. Instruments Methods Phys. Res. Sect. A Accel. Spectrometers, Detect. Assoc. Equip. 806 (2015) 109-116. https://doi.org/10.1016/j.nima.2015.09.088.

[56] J.F. Ziegler, SRIM-2008 (Stopping Power and Range of Ions in Matter), (2008). http://www.srim.org/.

[57] R.E. Stoller, M.B. Toloczko, G.S. Was, A.G. Certain, S. Dwaraknath, F.A. Garner, On the use of SRIM for computing radiation damage exposure, Nucl. Instruments Methods Phys. Res. Sect. B Beam Interact. with Mater. Atoms. 310 (2013) 75-80. https://doi.org/10.1016/j.nimb.2013.05.008.

[58] ASTM International, AE521-96: Standard Practice for Neutron Radiation Damage Simulation by Charged-Particle, 2009. https://doi.org/10.1520/E0521-96R09E01.

[59] M.K. Miller, K.F. Russell, K. Thompson, R. Alvis, D.J. Larson, Review of Atom Probe FIB-Based Specimen Preparation Methods, Microsc. Microanal. 13 (2007) 428436. https://doi.org/10.1017/S1431927607070845.

[60] J.M. Hyde, C.A. English, Symposium R: Microstructural Processes in Irradiated Materials, in: MRS 2000 Fall Meet., 2000.

[61] L.T. Stephenson, M.P. Moody, P. V. Liddicoat, S.P. Ringer, New techniques for the analysis of fine-scaled clustering phenomena within Atom Probe Tomography (APT) data, Microsc. Microanal. 13 (2007) 448-463. https://doi.org/10.1017/S1431927607070900.

[62] C.A. Williams, D. Haley, E.A. Marquis, G.D.W. Smith, M.P. Moody, Defining clusters in APT reconstructions of ODS steels, Ultramicroscopy. 132 (2013) 271-278. https://doi.org/10.1016/j.ultramic.2012.12.011.

[63] B.M. Jenkins, A.J. London, N. Riddle, J.M. Hyde, P.A.J. Bagot, M.P. Moody, Using alpha hulls to automatically and reproducibly detect edge clusters in atom probe tomography datasets, Mater. Charact. 160 (2020) 110078. 
https://doi.org/10.1016/J.MATCHAR.2019.110078.

[64] P.D. Edmondson, C.M. Parish, R.K. Nanstad, Using complimentary microscopy methods to examine Ni-Mn-Si-precipitates in highly-irradiated reactor pressure vessel steels, Acta Mater. 134 (2017) 31-39. https://doi.org/10.1016/j.actamat.2017.05.043.

[65] B.M. Jenkins, J.O. Douglas, N. Almirall, N. Riddle, P.A.J. Bagot, J.M. Hyde, G.R. Odette, M.P. Moody, The Effect of Composition Variations on the Response of Steels Subjected to High Fluence Neutron Irradiation, Materialia. 11 (2020) 100717. https://doi.org/10.1016/j.mtla.2020.100717.

[66] G.R. Odette, G.E. Lucas, Recent progress in understanding reactor pressure vessel steel embrittlement, 1998. https://doi.org/10.1080/10420159808229676.

[67] G. Bonny, A. Bakaev, D. Terentyev, E. Zhurkin, M. Posselt, Atomistic study of the hardening of ferritic iron by Ni-Cr decorated dislocation loops, J. Nucl. Mater. 498 (2018) 430-437. https://doi.org/10.1016/j.jnucmat.2017.11.016.

[68] D. Terentyev, A. Bakaev, Radiation-induced strengthening and absorption of dislocation loops in ferritic Fe-Cr alloys: The role of $\mathrm{Cr}$ segregation, J. Phys. Condens. Matter. 25 (2013). https://doi.org/10.1088/0953-8984/25/26/265702.

[69] T.P. Davis, J.C. Haley, S. Connolly, M.A. Auger, M.J. Gorley, P.S. Grant, P.A.J. Bagot, M.P. Moody, D.E.J. Armstrong, Electron microscopy and atom probe tomography of nanoindentation deformation in oxide dispersion strengthened steels, Mater. Charact. 167 (2020) 110477. https://doi.org/10.1016/j.matchar.2020.110477. 